I have used it also with satisfactory result in the performance of iridectomy, whether preliminary to extraction or for other reasons; not of course in glaucoma cases. There appears to me to be only one possible contra-indication and that obviously would be in the case of a patient known to have suffered from local atropin irritation; fortunately, in my experience in all cases, the conjunctiva will tolerate atropin for a considerable period of time, unless it has previously suffered from this complication.

Obviously, when the atropin solution is dropped into the conjunctival sac, and the section immediately proceeded with, the alkaloid in very considerable strength must make its way into contact with the iris, and in a strength out of all proportion greater than that which we can ever get by the usual methods of application in the after-treatment of a cataract case.

The BRitish Journal of Ophthalmology has so wide a circulation that $\mathrm{I}$ have thought it wise to bring a short note of this procedure before its readers, in the hope that many operators will test its efficacy, and possibly, at a later date, express their opinion upon it. I cannot but think that it is a very practical and simple way of improving our results in cataract extraction.

\title{
INJURY TO THE EYE, COMPLICATED WITH ABSCESS OF THE BRAIN AND TERMINATING FATALLY; AUTOPSY : TWO CASES
}

BY

\author{
G. Victor Miller, M.D.,
}

OPHTHALMIC AND AURAL SURGEON TO THE STOCKTON AND THORNABY HOSPITAL AND NORTH ORMESBY HOSPITAL, MIDDLESBROUGH.

1. A boy, aged 9 years, when playing football on Saturday, November 4, 1916, fell down. Whilst lying on the ground he received a kick from another boy over the right eye. He was dazed by the force of the blow, but not rendered unconscious. He walked home and there had his eye bathed. His parents continued this treatment until the morning of Tuesday, November 7, 1916, when they decided to take him to the Stockton and Thornaby Hospital, as his eye did not seem to be progressing favourably. The patient walked into the out-patient department at $10.30 \mathrm{a} . \mathrm{m}$. on Nov. 7 suffering from an injury to the right eye, and was seen by the house surgeon. On examination, the right upper and lower eyelids were seen to be markedly swollen and dark-coloured due to effusion of blood. There was a small laceration of the upper lid at the inner canthus and there was a slight exudation of pus from beneath the upper lid at its inner end. The eyeball itself seemed uninjured and 
patient was able to see quite well with it. Both pupils were dilated, equal, though sluggish in their reaction to light. Patient did not complain of pain in the eye and there was no subconjunctival haemorrhage. His general condition seemed fair, and he spoke quite clearly and rationally and did not exhibit cerebral symptoms of any kind. He was admitted to the children's ward about 10.45 a.m. the same day. His temperature on admission was $97 \cdot 6^{\circ} \mathrm{F}$., pulse 120 , respirations 26 . At $4.30 \mathrm{p} . \mathrm{m}$. he was seen by me. The effusion into the lids was very marked. The inner end of the upper lid was torn from its attachment. The eyeball seemed rather proptosed and fixed, its movement in all directions being very limited. The child appeared to be ill, was pale and restless, and evinced a definite dislike to being disturbed. The eye was bathed with mercury perchloride lotion $(1: 6,000)$, a drop or two of atropin instilled, and a light dressing placed over the eye and fixed with zinc plaster. The boy answered questions intelligently, and I certainly did not anticipate a rapid and fatal termination. At about 5.30 p.m., one hour after seeing him, the patient became delirious and got out of bed twice. At 6 p.m. he became unconscious. The temperature rose to $100^{\circ} \mathrm{F}$., the pulse became uncountable, and he exhibited CheyneStokes breathing. He became very rapidly worse and died at 6.30 p.m. the same day : that is, about eight hours after admission.

Autopsy.---On removing the brain it was found he had a fracture of the os planum of the ethmoid on the right side and also a fracture of the cribriform plate of that bone. The end of a pair of forceps could be passed from inside the skull down through the opening in the cribriform plate to the opening in the os planum. The opening in the cribriform plate was considerably larger than that in the os planum. In addition, there was an abscess affecting the anterior inferior surfaces of the frontal lobes of the cerebrum. There was a quantity of markedly yellow pus and of thick sanguineous material typical of pus in the early stages of formation. The whole necrotic and purulent area was about the size of a Tangerine orange. No cerebral hæmorrhages were seen. Patient had obviously received a violent blow from a boot; a boot which most probably had a metal toe-plate, such as is often worn by the poorer classes. Some dirt also had evidently been conveyed to the seat of fracture, thus giving rise to the acute infection and rapid fatal termination.

2. A girl, aged 6 years, was admitted to Stockton and Thornaby Hospital on November 9, 1916. The history was that she had been playing with another small child, who had struck her in the eye with a stick. On November $10 \mathrm{I}$ saw her and the eyelids were slightly swollen. She was given a general anaesthetic, and on separating the lids all that could be made out was a wound or tear in the upper part of the plica semilunaris. This was 
indicated by a red patch, about the size of a split pea. Boric fomentations, to be changed four times daily, were ordered. On November 13, when I saw her, the lids were much more swollen, and there appeared to be definite orbital cellulitis. I gave instructions for her to be prepared for a general anaesthetic the following morning when I proposed to make an incision into the orbit. Unfortunately at 9.30 p.m. on Nov. 13 she was seized with convulsions. The eyes rolled from side to side. Temperature was $106^{\circ} 6^{\circ} \mathrm{F}$. in rectum. Pulse uncountable. Cheyne-Stokes breathing. A small amount of haemorrhage from both nostrils. In fact, she had an attack like the previous case, but recovered.

On Nov. 14 I made a free incision into the orbit immediately below the inner end of the supraorbital margin and let out a considerable quantity of pus. A fairly large drainage tube was put well down to the bottom of the orbit. The child was better after this, but we observed she had lost the power of speech and the left arm was paralysed. We concluded there had been a serious brain infection, as in the previous case. On Nov. 22, I decided to trephine over the right Rolandic area with a view to getting at the cause of the loss of speech, etc. I first of all opened up the orbital wound thoroughly but could find nothing unusual. The opening in the skull was made with a $\frac{3}{4}$-inch trephine and then enlarged to some extent in all directions with bone forceps. I passed sinus forceps into the brain substance in various directions, but did not evacuate pus. Patient stood the operation well, and the wound quickly healed. She went on in this condition, with a slightly fluctuating temperature, but never above $101^{\circ} 2^{\circ} \mathrm{F}$. until December 10 , when she was not so well. There seemed to be considerable tension and irritation at the site of trephining. It was decided to open the wound up again, and when the skin was turned back, a large quantity of pus squirted up out of the brain substance, but one could not make out a track from which it came. The child was much better in every way after this, for a time. The day after Christmas Day, she suddenly began to talk, and did so quite rationally. She appeared also to get a little power back into the left arm. The child continued very well up to January 9, talking naturally, recognizing her relatives, eating and sleeping well. At this time she began to develop a large hernia cerebri. She lost flesh, and later there was loss of power in both left arm and leg. She was given an anaesthetic again, and an attempt made to deal with the hernia by turning back the skin flap and slicing off a portion of the brain tissue. But this proved very unsatisfactory; the hernia began to bulge again more than ever.

The patient lingered on in this rather hopeless condition until March 8, when she died.

On March 9,1917, a post-mortem examination was made and the 
following found.-Very extensive abscess of the frontal lobe of the right side of the brain. No signs of fracture of the orbital plate of the frontal bone or of the ethmoid bone. There were patches of meningitis on the dura mater of the right side. In short, the frontal lobe was broken down and bathed in a large quantity of pus.

\title{
Remarks
}

In conclusion, I may say these two cases point to the necessity of making free incisions into the orbit early where cellulitis is suspected and of not waiting for "pointing" and a feeling of fluctuation. Further, if the skull is opened, an attempt should be made to open as close to the site of injury as possible.

\section{A NOTE UPON THE PSEUDO-NEOPLASTIC FORM OF INTERSTITIAL KERATITIS}

\author{
BY \\ Sydney Stephenson, \\ LONDON.
}

WHILE reading the account given by Dr. F. A. Marchi in the November (1916) number of the Archivio di Ottalmologia of a couple of cases where trachomatous pannus appeared under the guise of a tumour (for abstract see THE BRITISH JOURNAL OF OPHTHALMOLOGY, September, 1917), I was reminded of an appearance seen, although rarely, in cases of interstitial keratitis. I have met with but few instances of this striking and curibus clinical picture, but have little doubt that others, besides myself, are familiar with it, although, so far as I know, it has not been specially described before.

The cases have all occurred in young subjects, who presented some of the ordinary stigmata of hereditary syphilis. Once only have I seen both corneae affected at the same time, although on several occasions, in my own experience, the condition has occurred first in one eye and then in the other. The clinical picture has been always the same, and may be briefly outlined as follows.-Occupying the upper or the lower part of the cornea, in the position of a so-called "Hutchinson's salmon patch," has been a somewhat prominent, fleshy-looking mass, at first sight resembling nothing so much as a neoplasm. The cornea adjoining the central part of the edge of the mass has shown interstitial deposits, or in more advanced cases, the entire cornea, not occupied by the growth, has exhibited the appearances of aggressive interstitial keratitis. In course of time the fleshy-looking mass has lost its prominence, so 